\begin{tabular}{|l|l|l|}
\hline & \\
PUCRS & HUMANIDADES & $\begin{array}{l}\text { Educação por escrito, Porto Alegre, v. 12, n. 1, p. 1-14, jan.-dez. } 2021 \\
\text { e-ISSN: 2179-8435 }\end{array}$ \\
\hline http://dx.doi.org/10.15448/2179-8435.2021.1.35052 & \\
\hline
\end{tabular}

SEÇÃO: ARTIGO

\title{
Proposta de modelo de gestão estratégica para instituições de educação básica confessionais
}

\section{Strategic management model proposal for confessional basic education institutions}

\author{
Alexandre de Souza ${ }^{1}$ \\ orcid.org/0000-0001-9798-3733 \\ alexandre.souza@lasalle.org.br
}

\section{Carlos Eduardo}

\section{Carvalho ${ }^{1}$}

orcid.org/0000-0002-7157-0743 carlos.carvalho@unoesc.edu.br

Recebido em: 27/07/2019 Aprovado em: 03/11/2020. Publicado em: 26/06/2021.
Resumo: Durante a maior parte da história do Brasil, os colégios confessionais consolidaram-se com uma proposta educativa baseada na formação integral da pessoa, sem preocupar-se com concorrência. Com a alteração da Lei de Diretrizes de Base, de 1996, que permitiu a entrada de grupos empresariais no setor educacional, muitos desses colégios fecharam as portas, diante da expertise em gestão dos novos concorrentes. A escola confessional precisou aprender a conciliar essa nova dimensão ao projeto pedagógico. Tendo em vista a importância histórica e social dessas instituições, o atual cenário da educação básica privada do Brasil e o escasso conhecimento sobre o assunto, este artigo propõe um modelo de gestão estratégica para uma Rede de Educação Confessional. Trata-se de um estudo de caso qualitativo. Os instrumentos de pesquisa utilizados foram: coleta de dados na sede da Rede, entrevistas semiestruturadas com os gestores e questionários com os diretores de escolas. Os resultados evidenciam a implantação de uma cultura de gestão estratégica na Rede e a atualização do modelo de gestão estratégica, a partir do Balanced Scorecard. Este artigo contribuiu com a discussão do tema da gestão estratégica em escolas confessionais, possibilitando a integração de elementos da gestão e da confessionalidade.

Palavras-chave: Gestão estratégica. Gestão educacional. Educação básica. Escola confessional.

Abstract: For most of Brazil's history, denominational colleges have been consolidated with an educational proposal based on the integral formation of the person, without worrying about competition. With the amendment of the Basic Guidelines Act (LDB) of 1996, which allowed business groups to enter the education sector, many denominational colleges have closed their doors in view of the management expertise of new competitors. The confessional school had to learn to reconcile this new dimension with its pedagogical project. Given the historical and social importance of these schools, the current scenario of basic education in Brazil and the scarce knowledge on the subject, this article proposes a strategic management model for a Confessional Education Network. This is a qualitative case study. The research instruments used were data collection at the headquarters of the Network, semi-structured interviews with managers and questionnaires with school principals. The results show the implementation of a strategic management culture in the Network and the updating of its strategic management model, based on Balanced Scorecard (BSC). This article contributed to the discussion of the strategic management theme in confessional schools, enabling the integration of elements of management and confessionality.

Keywords: Strategic management. School management. Basic education. Confessional school. 


\section{Introdução}

Instituições de educação básica confessionais são colégios mantidos por congregações religiosas e que apresentam uma proposta educativa baseada na qualidade pedagógica, formação integral da pessoa e vivência de valores humanos e religiosos. Cabe destacar que este estudo tem como foco as escolas confessionais católicas. Moura (2000), Brighenti (2006) e Pereira (2013) destacam a importância histórica e social da escola católica no Brasil, tendo em vista que a educação foi praticamente assumida pela Igreja Católica, durante o periodo colonial até Marquês de Pombal, e, posteriormente, contribuiu com a criação de diversas instâncias e legislações educacionais.

Essas instituições sofreram forte impacto com as alterações da Lei de Diretrizes de Base (LDB) de 1996, que regulamentou a participação da livre iniciativa do setor privado no campo educacional, facilitando a abertura de escolas com fins lucrativos. Criou-se, portanto, um mercado para o ensino no Brasil. O alto poder de investimento de grupos empresariais e a gestão empresarial focada em resultados, aumentaram a competitividade de um setor que, até então, não se preocupava com a concorrência. "Houve, então, naturalmente uma forte abertura do mercado a novos entrantes, modificando para sempre o cenário competitivo do setor" (TREVISAN \& TREVISAN, 2010, p. 188).

Nesse periodo, várias escolas particulares foram abertas por grupos empresariais, ao mesmo tempo que as católicas perderam espaço. Segundo o Sindicato dos Estabelecimentos de Ensino de São Paulo, em 1996 havia 2.556 escolas para atender 1,1 milhão de alunos; em 2003 havia 6.047 escolas para 1,3 milhão de alunos, ou seja, em 1996 havia 430 alunos por escola e em 2003 apenas 215 (TREVISAN \& TREVISAN, 2010).

Enquanto grupos empresariais desembarcavam no setor, injetando grandes investimentos, visando lucro com a educação, trazendo inúmeras inovações em relação à educação e estruturas fisicas modernas, as escolas confessionais demoravam em reagir, sentiam-se ameaçadas, criticavam o modelo de gestão empresarial na educação, ao mesmo tempo em que perdiam alunos e precisavam fechar várias unidades.

A demora por uma reação da escola confessional ocorreu, em boa parte, em virtude da própria história da Educação no Brasil. Segundo Steinberg e Marcatti (2010), houve um tempo em que palavras como "educação" e "negócio" não podiam ser pronunciadas numa mesma frase sem que fossem acompanhadas de uma saraivada de críticas. Os autores sinalizam a existência de uma forte visão "romântica" de acadêmicos, que condenavam a associação do conceito "instituição de ensino" ao de "empresa", no qual aluno e familia são clientes e que a escola precisa permanecer rentável e dar lucro. Os autores atribuem essa concepção ao início da educação no Brasil, em que os jesuitas a fizeram com uma forte tradição humanista, e que o ensino se vinculava aos mais altos valores humanos e cristãos e jamais ao "vil metal". Ao mesmo tempo em que muitos colégios eram fechados, a possibilidade de implementar os elementos de gestão do mercado, como uma resposta de mudança e sobrevivência, era vista como traição, ou mesmo, abandono dos ideais e valores centrais dessas organizações.

Segundo Steinberg e Marcatti (2010, p. 271), com o tempo, as escolas católicas foram compreendendo que "é preciso ter capital para poder fazer o bem". Não há outra maneira para a sobrevivência dos colégios confessionais, senão a de se compreenderem como empresas e buscarem apoio de ferramentas do mercado, para profissionalizar a gestão das escolas. Para essas instituições levarem adiante os seus ideais, que se concretizam em uma proposta educativa de formação integral da pessoa, será necessário adaptar os modelos de gestão, superando a incompatibilidade da administração utilitarista e da organização humanista.

Notícias recentes apontam que o mercado educacional continua acirrado (Associação Nacional das Escolas Católicas - ANEC, 2017). Novas aquisições e investimentos elevados de grupos empresariais sinalizam um aumento ainda maior no setor. Diante desse cenário, a própria ANEC (2017) orienta as escolas associadas a qualificar a administração com técnicas de administração atualizadas e eficientes, 
ao mesmo tempo em que necessita permanecer sólida sobre os principios fundamentais do cristianismo e do carisma da instituição. Estudos demonstram a possibilidade de integrar a gestão e os valores presentes nas escolas confessionais. Dalvit (2007), Paier (2008) e Mariucci (2011) demonstram o esforço que algumas instituições de educação básica confessionais realizaram nos últimos anos para atualizar a sua cultura organizacional, garantindo um posicionamento estratégico no atual mercado educacional, sem distanciar-se dos valores e da proposta pedagógica.

Diante desse cenário, este artigo analisou o contexto da implantação de uma cultura de gestão estratégica em uma rede confessional de ensino, a Rede La Salle de Educação, com o objetivo de elaborar um modelo de administração estratégica, a partir do Balanced Scorecard (BSC), integrando elementos da gestão e da confessionalidade. Os instrumentos utilizados na pesquisa foram: coleta de dados na sede da Rede; entrevistas com os gestores da Rede; questionário com diretores de escolas da Rede.

Este artigo contribui com o aprimoramento da gestão estratégica da Rede La Salle, através da atualização do modelo de administração, favorecendo a concretização da missão organizacional. Este artigo, também, contribui com a discussão do tema em Instituições Educacionais Confessionais, tendo em vista os escassos estudos nessa área.

\section{A escola confessional católica no Brasil}

Segundo Moura (2000), os primeiros registros de educação no Brasil sinalizam a atuação dos jesuitas Padre Manoel da Nóbrega e José de Anchieta, como os primeiros educadores do Brasil. Conforme Brighenti (2006), a educação no país foi praticamente assumida pela Igreja Católica, durante o período colonial até Marquês de Pombal. O empreendimento missionário jesuítico junto aos indios foi alvo de graves conflitos com os bandeirantes e com a Coroa portuguesa. Segundo Brighenti (2006), esses conflitos ficaram frequentes, pois o projeto catequético e educativo dos jesuitas, junto aos indigenas, impedia e coibia os interesses escravagistas dos bandeirantes. Em
1759, Marquês de Pombal expulsa os jesuitas de Portugal e de suas colônias.

Após essa expulsão, Marquês de Pombal empreendeu um primeiro projeto de ensino público (RIBEIRO, 1986), com a instituição das escolas régias. Ainda que esse fato tenha sido a primeira formulação de política pública de ensino, foi incapaz de promover amplo acesso à educação. Com a reforma pombalina, mais do que uma alteração, as diretrizes da Coroa destruíram todo o sistema educacional, implantado pelos jesuitas até então (SAVIANI, 2011). Exemplos dessa desconstrução foram o abandono e a pilhagem das bibliotecas dos colégios e residências dos jesuitas, em que a imensa maioria dos catecismos produzidos em línguas nativas da Colônia desapareceu.

Mesmo com o início de uma educação pública, esta continuou fortemente ligada à Igreja. Segundo Moura (2000, p. 65), a educação que acontecia, quase que exclusivamente nos colégios confessionais, passou a ser ministrada nas escolas régias, por mestres nomeados pelos bispos, padres e capelães do engenho, que se tornaram, depois da saída dos jesuítas, os principais responsáveis pela educação dos meninos brasileiros.

Em 1827, com a Lei das Escolas das Primeiras Letras, foi determinada a criação de escolas em todas as cidades e lugares mais populosos do Império. É preciso notar, entretanto, que, apesar das iniciativas do governo e da Igreja, durante o Império, a educação no Brasil continuou bastante precária, constituindo-se, em grande parte, em um privilégio, em razão do nascimento ou da posição social dos indivíduos (BOSCHILIA, 2002, p. 34).

Em novembro de 1889, o Império deu lugar à República dos Estados Unidos do Brasil, momento em que ocorreu a separação entre o Estado e a Igreja. Nesse periodo, foram apresentados vários projetos sobre a importância da educação para o progresso do país, apontando a instrução pública, gratuita e laica como exigência para o ingresso do Brasil na modernidade. Segundo Moura (2000), a lgreja foi se consolidando como importante parte organizada da sociedade, tendo em vista o aumento de colégios, obras sociais e hospitais. Essa realidade fez com que o poder público não 
deixasse a religião de lado. Nesse sentido, a lgreja se fez ouvir na elaboração das Constituições Federais de 1934 e 1937. A influência católica na elaboração dessas Constituições fez voltar o ensino religioso às escolas e abriu-se a possibilidade de o Estado subsidiar as instituições católicas que tivessem finalidade social (BUFFA, 1991).

Em 1945 foi criada a Associação de Educação Católica do Brasil. Desde a sua criação, essa associação manteve forte presença nas discussões sobre politicas voltadas à educação. Em 1944, ajudou a fundar o Sindicato dos Estabelecimentos Particulares de Ensino e atuou junto aos deputados e órgãos de comunicação, para defender e veicular as ideias e propostas dos colégios católicos sem relação à legislação educacional no país.

Em 1961, com a Lei $n^{\circ} 4.024$, foram fixadas as Diretrizes e Bases da Educação Nacional. Foi uma primeira política pública educacional voltada para atender à necessidade da população brasileira, ainda sem acesso à escola. Essa lei estabeleceu a criação dos Conselhos de Educação, e vários bispos e padres, ligados à educação católica, foram escolhidos para comporem esses conselhos, o que demonstra a força e a importância da educação dessa religião na construção dos alicerces da educação brasileira.

Em 1996, o Governo Federal aprovou a nova LDB, que regulamentou a participação da livre iniciativa do setor privado no campo educacional, facilitando a abertura de escolas com fins lucrativos. Até então, esse setor era formado somente por colégios confessionais ou por escolas de grupos familiares. $O$ alto poder de investimento de grupos empresariais e a gestão empresarial focada em resultados aumentaram a competitividade desse setor. Em poucos anos, notou-se o fechamento de inúmeras escolas católicas, ao mesmo momento, em que são abertas novas particulares, por grupos empresariais (CENTRO DE ESTATISTICA RELIGIOSA E INVESTIGAÇÕES SOCIAIS, 2006).

Os colégios católicos precisaram aprender a integrar as ferramentas de gestão junto aos valores confessionais, para continuar levando adiante a sua missão. Nesse contexto, pouco favorável para as escolas católicas, foi criada a ANEC, com o objetivo de acompanhar as mudanças na legislação, para possibilitar uma presença mais forte das escolas católicas diante dos órgãos federais, contribuindo para a concretização de uma educação religiosa de qualidade no Brasil.

É importante destacar que a escola confessional católica deve garantir os mesmos processos de qualquer outra, tanto no aspecto cultural quanto no pedagógico. O que tem de novo e deve ser a característica peculiar, é a busca pela vivência dos valores evangélicos e humanos. Pautados nesses principios, essas instituições agregam, nas práticas de ensino, valores, tais como o amor ao próximo, caridade, generosidade, tolerância, empatia, compaixão, cuidado com o outro e com o mundo ao redor, etc, buscando promover uma sociedade mais justa e fraterna para todos.

Segundo Kuzma (2013), é dessa maneira que a escola católica pretende colher frutos, quando os educandos, no exercício da própria liberdade, cumprirão o papel na sociedade em vista da promoção da justiça, da paz e do bem comum. Para tanto, a esses colégios não podem estar parados e fechados em si mesmos, mas devem evoluir de acordo com o tempo. Digamos assim: se é uma escola, está aberta aos avanços e às descobertas do saber; se é católica, traz para sua definição o que é característico do ser católico, que significa estar aberto ao mundo, pois apenas acolhendo e compreendendo é que se pode ousar dar uma resposta capaz de transformar, de produzir algo novo e concreto.

\section{Elementos para uma gestão estratégica na escola confessional}

É recente o uso do conceito "gestão" na dinâmica escolar. Esse conceito nasceu dentro das Ciências Sociais Aplicadas, mas acabou sendo incorporado por outras áreas do conhecimento. O termo está diretamente relacionado com administração, que é a maneira de conduzir uma organização para alcançar objetivos e metas.

As escolas, durante a trajetória histórica, buscaram estabelecer os meios necessários para garantir o bom funcionamento. Portanto, a ideia de planejar, dirigir e avaliar esteve presente nessa instituição, 
porém, mediante organizações simples, possivelmente, mais vinculadas à organização escolar. Nas últimas décadas, percebe-se a incorporação do termo gestão nas escolas, nos cursos de formação de professores, bem como nos documentos do governo e do Ministério da Educação e Cultura.

De acordo com Paro (2012), a atividade-fim da escola é o ensino e aprendizagem, e esta precisa prevalecer. As diferentes maneiras de organização ou administração escolar são meios necessários para atingir a finalidade educacional, que está associada à qualidade das aprendizagens dos alunos e a formação de cidadãos críticos. Romero (2009) defende que um bom processo de gestão se relaciona com o de construção de uma escola de qualidade. Planejamento estratégico, uso de indicadores qualitativos e quantitativos e avaliação institucional são instrumentos que os gestores educacionais precisam estar cada vez mais familiarizados, em razão de conseguinte contribuição para o processo de administração escolar. Lück (2000) afirma que a responsabilidade educacional exige profissionalismo. São inúmeros os espaços e processos que o gestor educacional precisa gerenciar na atualidade: desenvolver trabalhos em equipe; monitorar resultados; planejar e implementar o projeto político pedagógico da escola; coordenar reuniões eficazes, etc.

Ao pensar a gestão escolar nos colégios confessionais, Murad (2008) afirma que essas instituições nasceram e se desenvolveram a partir de um ideal, de uma mística, e que seus projetos pedagógicos compreendem visão de pessoas, de educação e de mundo inspiradas por valores humanos e religiosos, visando à construção de um mundo mais justo, fraterno e solidário. Assim, essas organizações enfrentam o desafio de terem de buscar maior profissionalismo e técnicas de gestão sistematizada, para poderem levar adiante sua proposta no mundo atual. Segundo Murad (2008, p. 13), o desafio está em conciliar os valores à eficácia necessária da gestão. Qualquer organização, seja lucrativa ou não, só realizará sua missão se colocar em prática os principios da gestão.

Nota-se, portanto, a necessidade crescente de articular processos de administração na escola, para que a mesma possa concretizar sua missão com mais eficiência e qualidade. Essa necessidade é ainda maior e urgente para os colégios confessionais, tendo em vista o atual cenário do mercado da educação privada brasileira. A ANEC (2017) realizou uma pesquisa a respeito da educação básica no Brasil, sinalizando que esse mercado, caracterizado por escolas de pequeno e médio porte, no qual os grupos de maior relevância eram formados por confessionais, está em alteração. Em notícia recente, publicada em março de 2017, a revista Isto é Dinheiro comenta que o ensino básico está atraindo grandes investidores locais e globais, com grandes investimentos nesse mercado, que já movimenta R\$ 51 bilhões (KROEHN, 2017).

Diante desse cenário, a pesquisa da ANEC (2017) sinaliza a importância de uma gestão eficaz nas escolas católicas. Percebe-se que muitas instituições ainda fazem a gestão com base em achismo ou feeling e, por isso, ou não conseguem atingir os objetivos traçados inicialmente ou os atingem parcialmente. Esta pesquisa apontou alguns caminhos para a educação católica, entre eles: permanecer sólida sobre os principios fundamentais do cristianismo e do carisma da instituição e gerenciar de acordo com técnicas de administração atualizadas, eficientes e justas.

Em sintonia com as orientações da ANEC, percebe-se que muitas escolas e Redes de Educação Confessionais estão conseguindo se posicionar nesse novo cenário da educação no Brasil. Conforme demonstraram Dalvit (2007), Paier (2008) e Mauricci (2011), as escolas ou Redes confessionais que estão conseguindo integrar os elementos de uma gestão profissional e atual, sem, contudo, distanciar-se dos valores da identidade confessional das suas redes de ensino, estão conseguindo se posicionar no mercado e ter melhores resultados, bem como buscar crescimento e expansão.

Um importante sistema de gestão, utilizado em diferentes organizações em todo mundo, que pode trazer importantes contribuições para as escolas confessionais, é o BSC. Esse sistema já é amplamente utilizado em instituições de ensino superior, inclusive nas confessionais, porém, em uma busca nas principais bases de dados, nota-se que esse é pouco aplicado na educação básica, principalmente entre as confessionais. 
O BSC pode contribuir com o gerenciamento estratégico das escolas confessionais, pois permite uma integração de ativos tangiveis e intangíveis, indo além do gerenciamento de indicadores contábeis e financeiros, agregando pessoas, processos e aprendizagem. O BSC possibilita que a missão, visão e valores da organização sejam traduzidos em estratégias e objetivos, que serão alinhados e integrados em toda a organização (KAPLAN \& NORTON, 2004). Ou seja, o sistema permite integrar os valores das instituições confessionais aos objetivos estratégicos, favorecendo a gestão estratégica.

O BSC tem início com a definição da estratégia organizacional e o seu desdobramento em quatros perspectivas: financeira; clientes; processos internos; aprendizagem e crescimento. Essas quatro perspectivas estão interligadas em um quadro denominado mapa estratégico. Cada perspectiva desse mapa agrega um conjunto de objetivos, metas, ações e indicadores, que precisa estar alinhado e integrado à estratégia organizacional. Essa proposta precisa ser adequada segundo a realidade de cada empresa. Não existe um conjunto padronizado de indicadores e metas. Cada instituição tem uma missão, uma visão, valores e uma estratégia e precisa elaborar e articular o seu mapa estratégico.

Segundo Kaplan e Norton (2004), esses indicadores estratégicos podem ser vistos não como medidas de desempenho isoladas, mas como uma série de relações de causa e efeito entre os objetivos, nas quatro perspectivas do BSC. O mapa estratégico, portanto, é uma representação gráfica dessas conexões e da integração da estratégia em toda a organização. A partir do topo, parte-se da hipótese de que os resultados financeiros somente serão alcançados se os clientes-alvo estiverem satisfeitos. A proposição de valor para os compradores descreve como gerar vendas e aumentar a fidelidade dos clientes-alvo. Os processos internos criam e cumprem a proposição de valor para os que contratam o serviço. Os ativos intangiveis, que respaldam os processos internos, sustentam os pilares da estratégia. O alinhamento dos objetivos nessas quatro perspectivas é a chave para a criação de valor e para uma estratégia consistente.

O BSC enriquece o processo de execução e gerenciamento do planejamento, e o mapa estratégico permite visualizar a estratégia integrada nas diferentes dimensões da organização, bem como visualizar os passos e as conexões realizadas para o alcance do objetivo. As medidas de desempenho oportunizam uma constante avaliação das metas e indicadores, permitindo uma análise de quais áreas estão correspondendo ao planejado e quais precisam de alterações. "O verdadeiro poder do BSC, todavia, ocorre quando deixa de ser um sistema de medidas e se transforma em um sistema de gestão estratégica" (KAPLAN \& NORTON, 1997, p. 20).

Um dos poucos estudos sobre a aplicação de BSC na educação básica foi realizado por Carvalho (2005). Essa pesquisa buscou integrar a gestão educacional com o gerenciamento estratégico, utilizando como base de estudo o Colégio Israelita Brasileiro, de Porto Alegre, RS. Como resultado, a autora sugeriu a revisão do posicionamento estratégico do colégio em questão e uma nova formulação do planejamento foi concebida e descrita em perspectivas estratégicas, objetivos e indicadores de desempenho, conforme proposto pelo BSC.

Segundo Neely e Bourne (2000), organizações em todo o mundo estão reestruturando seus sistemas de medição, adotando o BSC. Porém, afirma-se que 70\% das implementações de BSC falham. Segundo estudos dos autores, há dois motivos principais que explicam essas falhas. $O$ primeiro se refere à má projeção desses sistemas e o segundo à dificuldade de implementação. A má projeção está relacionada com o processo de decisão sobre o que medir, e a dificuldade de implantação refere-se sobre as estruturas de efetivação e acompanhamento do sistema de medição. Para Neely e Bourne (2000), a eficiência desse processo está associada à simplicidade e automação. O segredo é medir o mínimo possivel, porém medindo as coisas que realmente importam e a utilização da tecnologia para agilizar a leitura dos resultados. Muitas organizações simplesmente não conseguem extrair valor da medição de desempenho. Todo o processo de 
medir o desempenho é completamente desperdiçado, a menos que seja tomada uma ação com os dados que são gerados.

\section{Procedimentos metodológicos}

Esta pesquisa trata-se de uma investigação qualitativa, baseada em um estudo de caso. Segundo Yin (2010), o estudo de caso possibilita investigar experiências, fenômenos de acontecimentos da vida real, processos organizacionais e administrativos, entre outros. Consiste na análise profunda e exaustiva de um ou poucos objetos, de maneira que permita amplo e detalhado conhecimento sobre o objeto de pesquisa.

O estudo de caso em questão tem como objetivo apresentar um modelo de gestão estratégica para escolas de educação básica da Rede La Salle, a partir da análise do processo de implementação de uma cultura de gestão estratégica na Rede. O motivo da escolha por essa Rede deve-se à acessibilidade às fontes de informação, bem como à representatividade como uma importante rede confessional no país. Dentre o escopo do estudo, no que se refere às técnicas e instrumento de coleta de dados, foram utilizados a pesquisa documental, entrevistas e questionários.

A pesquisa documental foi realizada na sede da Mantenedora da Rede La Salle, localizada no municipio de Porto Alegre, capital do estado do Rio Grande do Sul, Brasil. Foram selecionados materiais que serviram de base para a pesquisa, como: documentos e atas, elaborados pela direção da Mantenedora e assessorias; publicações e orientações sobre planejamento estratégico; indicadores de desempenho e processos de gestão.

Foram realizadas entrevistas semiestruturadas com os Diretores de Gestão dos últimos dez anos, com o objetivo de compreender como foi o processo de implantação de uma administração estratégica na Rede. Foram entrevistados dois diretores de gestão, que atuaram nesse periodo, que foram identificados como Diretor de Gestão 1 e Diretor de Gestão 2. A opção por entrevistá-los ocorreu porque serem o principal assessor do Presidente da Rede, em relação à gestão estratégica. Também foram encaminhados questionários aos diretores das escolas da Rede que tiveram um desempenho acima da média. Para tal, foi averiguado quais as unidades que tiveram um desempenho superior às metas pedagógicas e administrativas estipuladas nos últimos dez anos, no mínimo, em 70\% do período analisado, ou seja, sete anos. De acordo com esses critérios, obteve-se um total de oito unidades, e esses diretores foram identificados como de Diretor A a Diretor H. Buscou-se entender, a partir desses questionários, que fatores contribuíram para que essas escolas alcançassem um resultado acima da média, que podem contribuir para a elaboração do modelo de gestão da Rede.

A elaboração do modelo de gestão para a Rede La Salle, objetivo deste estudo, foi realizada a partir da sintese da análise dos elementos obtidos na pesquisa documental, entrevistas com os gestores e questionários realizados com os diretores.

\section{Análise e discussão dos resultados}

Nesta seção são apresentados e discutidos os resultados obtidos na pesquisa. Primeiramente, será apresentada a análise do processo de implantação da cultura de gestão estratégica na Rede La Salle. Por fim será exposta a proposta de elaboração do modelo de gestão estratégica para a Rede, a partir do BSC.

\subsection{Implantação de uma cultura de gestão estratégica na Rede La Salle}

A Rede La Salle caracteriza-se pelo ensino confessional, pertencente à congregação dos Irmãos de La Salle. Possui mais de 300 anos de história e está presente em 77 países. Com mais de 100 anos de presença no Brasil, a Rede está presente em nove estados e no DF e conta com aproximadamente 50 mil alunos.

Assim como as demais redes de ensino confessionais, a Rede La Salle sofreu forte impacto com a alteração da LDB de 1996. Conforme Dalvit (2007), entre 1997 e 2006 houve uma diminuição de 55\% nas matrículas dos colégios lassalistas do Rio Grande do Sul, estado que concentra o maior número de escolas da Rede, e o fechamento de uma das unidades. Após esse periodo, essa rede de colégios 
estruturou sua gestão estratégica, qualificando o seu posicionamento no mercado e buscando o crescimento e sustentabilidade financeira.

A Rede La Salle possui, como missão organizacional, a formação cristã e integral das crianças e jovens, mediante ações educativas de excelência. A proposta educativa visa à formação integral da pessoa, por meio de uma educação de qualidade, baseada nos valores lassalistas e cristãos. Portanto, o termo "estratégia", no presente contexto, está relacionado ao conjunto de ações realizadas, estruturadas e/ou planejadas, direcionadas ao alcance da missão da Rede, objetivando a concretização da proposta educativa.

Segundo o Diretor de Gestão 1, que acompanhou a implantação de uma gestão estratégica na Rede, o cenário nesse periodo pode ser descrito da seguinte maneira:

Tinhamos algumas escolas indo bem e outras nem tanto. Isso dependia da direção que se tinha, do personalismo da pessoa que estivesse à frente, não dependia tanto de uma coordenação a nivel da Rede. O cenário de perda de alunos não era uma característica somente das escolas lassalistas, mas das escolas confessionais. Talvez a não qualificação suficiente, a não profissionalização de processos e de pessoas, a infraestrutura dos nossos colégios, que não era bem cuidada, tenha contribuido para a diminuição dos alunos na nossa Rede.

Esse relato está em sintonia com a percepção dos diretores de escola da Rede. Ao analisar esse periodo, basicamente, todos os diretores entrevistados apontaram a existência de elementos que caracterizam transição de administração familiar para gestão profissional. "Quando assumi a direção do colégio, encontrei, em termos de gestão, todos os processos centrados no diretor e na supervisão pedagógica, pouca circulação das informações, a estrutura fisica era antiga e mal conservada", destaca o Diretor C. "Em termos de organização interna, estava mal, sem mapeamento dos principais processos e com as ações baseadas mais nas pessoas e suas experiências do que em documentos padronizados e formais", destaca o Diretor $\mathrm{H}$.

Tendo em vista uma reação frente a esse cenário, a Rede buscou a implantação de um planejamento estratégico. Diferentemente do que sinalizaram Steinberg e Marcatti (2010), sobre a demora por uma reação da escola confessional diante desse novo cenário, percebe-se uma postura de abertura da Rede La Salle, já em 1998, buscando a primeira elaboração de um Planejamento Estratégico. Porém, segundo o Diretor de Gestão 1, apesar do vanguardismo para a elaboração do planejamento estratégico, a Rede encontrou dificuldades para execução nos anos seguintes. Possivelmente, a falta de experiência e conhecimentos específicos da área e as resistências resultantes da implantação de novos processos fizeram com que a Rede necessitasse de um tempo maior para a concretização do planejamento estratégico.

A partir de 2006, uma nova diretoria assumiu a direção da Rede, com objetivo de priorizar o trabalho. Nesse periodo, segundo o Diretor de Gestão 1, implantou-se um novo modelo de gestão para os colégios da Rede, o qual teve foco no trabalho da equipe diretiva, buscando a unidade de administração e o alinhamento das ações e decisões. Juntamente com essa ação, iniciou-se a padronização de processos administrativos e pedagógicos, centralização financeira, reuniões e capacitações, em nivel de rede, bem como reforçou-se as assessorias internas que acompanham os trabalhos realizados pelas escolas e o estabelecimento de metas e indicadores.

Atualmente, busca-se o aprimoramento desses processos e a informatização do planejamento estratégico das unidades, visando agilidade e credibilidade das informações e do sistema. Segundo o Diretor de Gestão 2, as rotinas e os procedimentos adotados pela direção da Rede têm contribuido para criar uma cultura de gestão de resultados nas escolas. Basicamente, quase todos os colégios da Rede conseguiram melhorar ou manter os resultados nos últimos anos. Percebe-se que, gradativamente, a cultura de uma administração estratégica vem se internalizando nas escolas da Rede, conforme percepções dos diretores:

A revisão e atualização do planejamento estratégico é um trabalho que envolve direção, serviços pedagógicos e administrativos e professores. Portanto, nossos objetivos estratégicos tornam-se conhecidos por toda a comunidade educativa e estão interligados com as ações da escola, como um todo. (DIRETOR A). 
Os resultados da escola estão melhorando a cada ano. Algumas metas eram dificeis de serem atingidas. Hoje, estamos com os principais resultados dentro da meta. Anualmente nós fazemos um levantamento com os pais e alunos dos pontos fracos e fortes da instituição, bem como das necessidades e prioridades das escolas, pois havia uma percepção que alguns investimentos que a escola fazia, não agregavam valor para a comunidade. A partir do final de 2011, os pais passaram a acompanhar as metas e os investimentos que a escola faz, a cada ano, através das reuniões de pais. (DIRETOR E).

O relato apresentado pelos diretores também está em sintonia com o que disse o Diretor de Gestão 2, sobre uma espécie de institucionalização da cultura de planejamento e resultados. Nota-se, atualmente, que o uso constante do planejamento estratégico, as reuniões de formação com os diretores da Rede, o acompanhamento das escolas pelas assessorias administrativas e pedagógicas e o estabelecimento de metas auxiliou a Rede a se reposicionar no mercado educacional, aumentando o número de alunos e de escolas durante os últimos anos. Em relação às dificuldades encontradas atualmente na administração, o Diretor de Gestão 2 pontua:

Talvez a dificuldade não seja desta ou daquela gestão, mas uma limitação que é própria das instituições religiosas, que é o jeito de se organizar e de ser presença em um mundo competitivo como o que estamos. Não creio que se deva profissionalizar ao estilo dos grupos comerciais, pois isso mataria o que é a instituição enquanto tal. Mas estamos dando passos e nos entendemos com a necessidade de profissionalizar processos, sem deixar de valorizar as pessoas. Penso que esta seja a principal dificuldade, equilibrar entre os que veem que precisaria avançar mais e os que estão acomodados em um estilo mais "familiar".

Percebe-se uma grande sintonia da fala do atual diretor de gestão da Rede com os desafios expressos por Steinberg e Marcatti (2010), Paier (2008) e Mariucci (2011), a respeito das escolas confessionais, as quais precisam incorporar as ferramentas e sistemas de gestão, utilizados constantemente no mercado atual, sem, contudo, enfraquecer a identidade católica e o compromisso com os valores humanísticos que caracterizavam a instituição. Em relação à confessionalidade, elemento central na identidade das escolas lassalistas, o Diretor de Gestão 2 destaca:

\begin{abstract}
As Escolas lassalistas se caracterizam por serem acolhedoras e tratarem a todos como importantes no processo educativo, por não quererem impor uma proposta educativa de mercado, por apresentarem experiências, momentos e projetos que incentivem a espiritualidade, o voluntariado e a participação comunitária. Estas e outras razões indicam que somos confessionais e ligados a uma religião, porque nos identificamos com a Igreja Católica. Isso que foi dito acima precisa estar na gestão de igual forma que na sala de aula, no atendimento ao público e na realização de projetos.
\end{abstract}

Os diretores de escolas da Rede têm a mesma percepção. É preciso qualificar e tornar a gestão mais profissional e, ao mesmo tempo, buscar garantir que os elementos da confessionalidade estejam presentes na administração e no cotidiano escolar. "Consideramos a confessionalidade como um ponto forte da nossa Rede. Muitas familias nos procuram exatamente em função da espiritualidade presente em nossas ações, assim como consideram primordial a acolhida e firmeza, heranças de São João Batista de La Salle", afirma o Diretor F. "Os colégios não confessionais estão vendendo os valores humanos, que temos em nossos principios filosóficos como mais um produto de mercado. A médio e a longo prazo a educação confessional poderá alcançar resultados positivos por ter em sua essência este princípio", destaca o Diretor C. "Eu acredito que a educação católica tem um nicho grande no mercado, pois a sociedade carece de valores, talvez o que está faltando é saber 'vender' esse diferencial", pontua o Diretor E.

$O$ diferencial estratégico de uma rede confessional está na própria essência. É preciso aprimorar a gestão, posicionar-se adequadamente e saber comunicar esse diferencial para a sociedade. Conforme descrito pelos diretores, é perceptivel que muitas familias buscam uma educação de qualidade para os filhos, com escolas modernas, que acompanham as tendências educacionais, que inovam. Porém, é grande a busca por escolas que educam e preparam para a vida e, também, que trabalham valores humanos. As redes confessionais já possuem esses elementos em sua essência, e uma gestão eficiente e profissional pode contribuir para a concretização dessa proposta no cenário atual. 


\subsection{Atualização do modelo de gestão estratégia da Rede La Salle}

Propomos utilizar o BSC no modelo de planejamento estratégico da Rede, pois o mesmo auxilia no processo de tradução da estratégia, indicando os passos necessários para alcançá-la. Além disso, - BSC permite a integração de ativos tangiveis e intangiveis, favorecendo a gestão estratégica de redes confessionais. A Figura 1 apresenta o processo de elaboração do mapa estratégico.

Figura 1 - Processo de elaboração do mapa estratégico

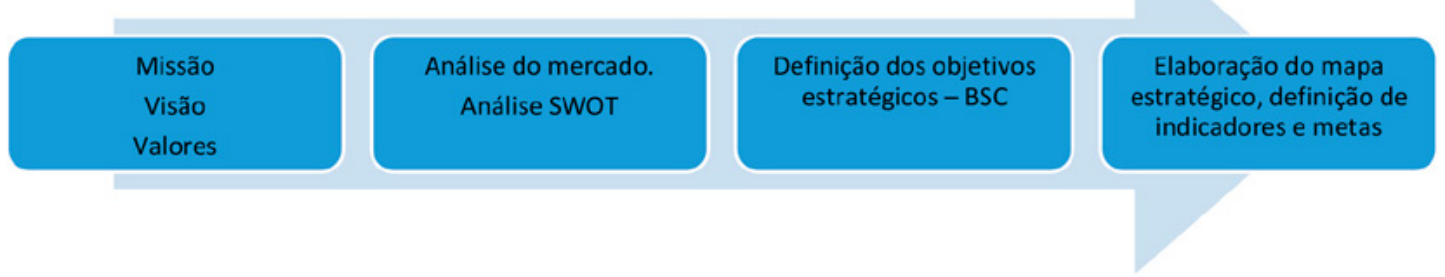

SWOT: strengths, weaknesses, opportunities e threats. Em português, é "análise FOFA" - forças, oportunidades, fraquezas e ameaças; BSC: Balanced Scorecard.

Fonte: Elaboração própria.

A missão, a visão e os valores representam diretrizes organizacionais e sinalizam os horizontes para a organização. A análise do mercado e a análise SWOT (ferramenta de gestão que possibilita uma análise interna e externa da organização), são importantes mecanismos de diagnóstico e contextualização da realidade local. A partir desses elementos, busca-se a definição dos objetivos estratégicos e a respectiva elaboração do mapa estratégico.

Os objetivos estratégicos são descritos nas perspectivas do BSC propostas para a Rede. Esses diferentes panoramas são interligados por relações de causa e efeito, buscando a integração da estratégia em toda a organização. O mapa estratégico estabelece indicadores e metas, que permitem o gerenciamento dos objetivos estratégicos. A Figura 2 apresenta a proposta de modelo de BSC para a Rede La Salle.

Figura 2 - Modelo de Balanced Scorecard para a Rede La Salle

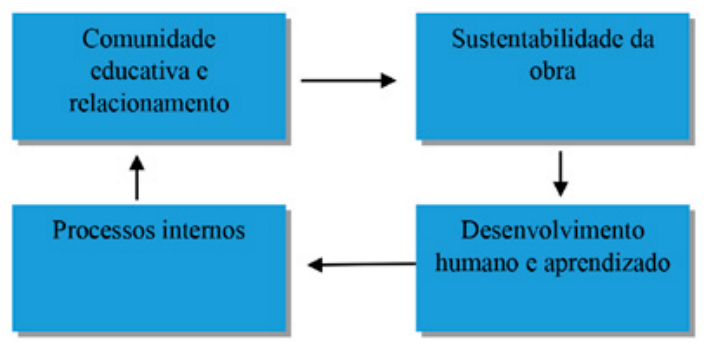

Fonte: Elaboração própria.
Nota-se que as perspectivas propostas para o BSC da Rede apresentam pequenas alterações em relação à nomenclatura oficial, proposta por Kaplan e Norton (2004). Percebeu-se como necessária essa adaptação pelo fato de as instituições de ensino serem organizações com características diferentes das empresas em geral, além de possuírem particularidades próprias relacionadas à confessionalidade. A Rede La Salle não tem como objetivo conquistar resultados financeiros, mas, sim, um forte componente de compromisso social e educacional, vinculados à manutenção e perenidade da obra.

A perspectiva financeira foi alterada para "sustentabilidade da obra". Esse ajuste justifica-se pela característica confessional da organização e sua busca por resultados mais amplos, não apenas financeiros. Percebe-se, também, que a mesma não está no ápice do modelo, mas interligada às demais. As unidades educativas lassalistas, ao alcançarem seus objetivos organizacionais, visam à sustentabilidade da obra. O alcance desse objetivo garante a retroalimentação das demais perspectivas, gerando um constante ciclo de aprendizagem e de qualificação de processos. A perspectiva de clientes foi alterada para "comunidade educativa" e relacionamento, também, por motivos da característica confessional, 
reforçando elementos da cultura. A perspectiva de processos internos não apresentou alteração, e a perspectiva de aprendizado e crescimento foi alterada para desenvolvimento humano e aprendizado, pelos mesmos motivos apresentados anteriormente.

Cada perspectiva apresenta objetivos relacionados a uma dimensão da organização. A de "sustentabilidade da obra" apresenta os objetivos relacionados com a manutenção e a qualificação da presença da Rede La Salle. Dessa forma, precisa conter elementos relacionados à sustentabilidade econômico-financeira da unidade, pois são os que garantem os investimentos em diferentes recursos para as demais perspectivas, bem como a perenidade da obra, a vivência dos valores lassalistas, qualidade nos processos educativos e a responsabilidade social. Os indicadores dessa perspectiva precisam sinalizar os resultados almejados para esses diferentes objetivos, conforme o planejamento estratégico e posicionamento de cada unidade.

A perspectiva "comunidade educativa e relacionamento" reúne objetivos relacionados à satisfação, percepção, reconhecimento e valorização dos diferentes membros da comunidade educativa lassalista - alunos, familias e colaboradores -, bem como, os diferentes públicos externos e de interesse da instituição. Alcançar os objetivos nessa perspectiva oportuniza a entidade a ter maiores chances de alcançar a sustentabilidade da obra. Para elaborar os objetivos estratégicos dessa, os gestores devem ser perguntar: como a escola onde atuo quer ser reconhecida pelos seus diferentes públicos? Que elementos da comunidade educativa e da interação com a comunidade local eu preciso acompanhar para garantir que a sustentabilidade da obra seja alcançada? Empregou-se o nome de "comunidade educativa e relacionamento" por entender o público-alvo da escola não como um segmento pronto para cobrar e receber (clientes), mas como sendo formado por grupos de diferentes pessoas que participam da geração de valor para a instituição. Essa perspectiva precisa apresentar indicadores de resultados relacionados a esse reconhecimento e percepção.

A perspectiva "processos internos" apresenta os objetivos relacionados aos processos-chave para que se possa alcançar os objetivos da "comunidade educativa e relacionamentos". Para elaborar as finalidades estratégicas dessa perspectiva, os gestores devem ser perguntar: quais são os principais processos internos que podem impactar o alcance dos objetivos da organização? Que processos eu preciso implantar ou reformular para que os objetivos da perspectiva da "comunidade educativa" e relacionamento sejam alcançados? Enfim, é necessário apresentar indicadores relacionados ao acompanhamento desses processos e à satisfação das pessoas que os utilizam.

A perspectiva "desenvolvimento humano e aprendizado" refere-se aos objetivos de desenvolvimento, capacitação e formação que oportunizarão maior efetividade nos processos internos da instituição. Para elaborar os objetivos estratégicos dessa perspectiva, os gestores devem ser perguntar: que esforços institucionais podem auxiliar a engajar pessoas na estratégia e fortalecer uma cultura de comprometimento e alcance dos resultados? Essa perspectiva precisa apresentar indicadores relacionados à formação de pessoas, gestão da inovação e busca de novos procedimentos, etc.

A seguir, são apresentados um exemplo de mapa estratégico e o conjunto de indicadores elaborados para uma das unidades da Rede, para facilitar o entendimento da aplicação desse modelo. O mapa estratégico, Figura 3, parte dos objetivos estratégicos, presentes no planejamento estratégico da unidade, enquadrando-os nas perspectivas sinalizadas no BSC da Rede La Salle, seguido de uma proposta de indicadores de desempenho para cada uma dessas perspectivas, conforme Quadro 1. 
Figura 3 - Mapa estratégico para uma unidade da Rede La Salle

\section{Mapa Estratégico}

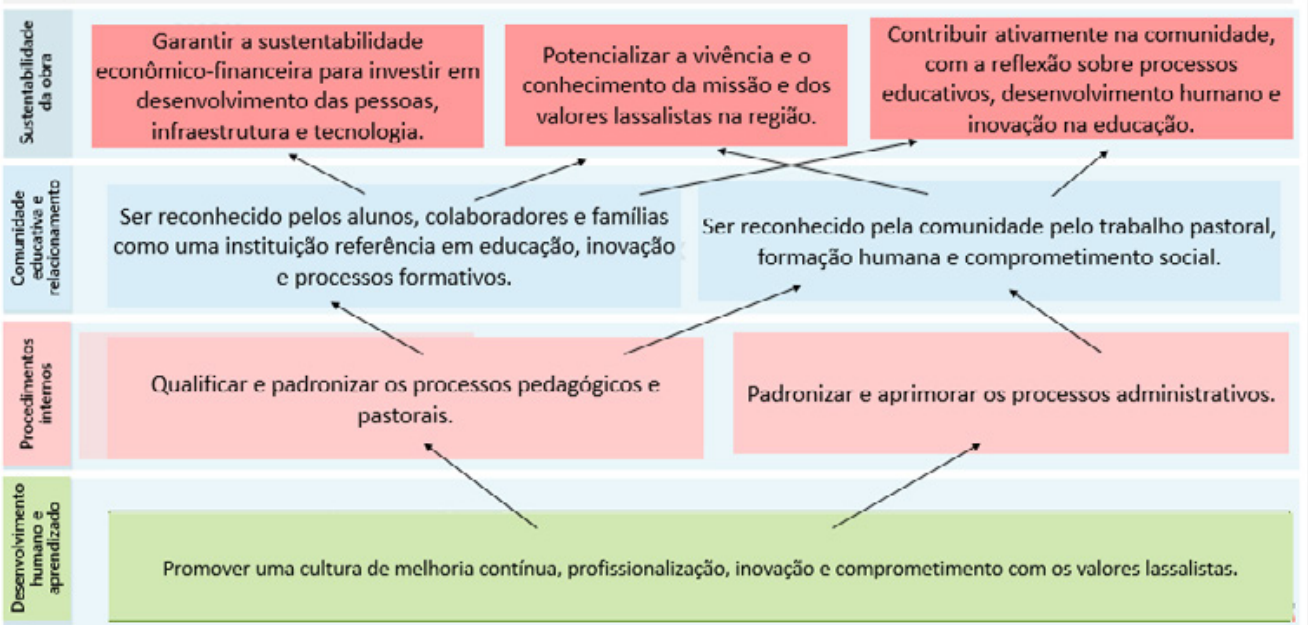

Fonte: Elaboração própria.

Quadro 1 - Proposta de mapa estratégico com indicadores

\begin{tabular}{|c|c|c|}
\hline $\begin{array}{l}\text { Perspectiva } \\
\text { estratégica }\end{array}$ & Objetivo estratégico & Indicadores \\
\hline $\begin{array}{l}\text { Sustentabilidade } \\
\text { da obra }\end{array}$ & $\begin{array}{l}\text { - Garantir a sustentabilidade econômico-fi- } \\
\text { nanceira para investir em desenvolvimento } \\
\text { das pessoas, infraestrutura e tecnologia. } \\
\text { • Potencializar a vivência e o conhecimento } \\
\text { da missão e dos valores lassalistas na região. } \\
\text { - Contribuir ativamente na comunidade, } \\
\text { com a reflexão sobre processos educati- } \\
\text { vos, desenvolvimento humano e inovação } \\
\text { na educação. }\end{array}$ & $\begin{array}{l}\text { - Inadimplência; } \\
\text { - comprometimento de folha; } \\
\text { - resultado financeiro; } \\
\text { - no de alunos; } \\
\text { - \% de rematrícula; } \\
\text { - no de projetos e campanhas reconheci- } \\
\text { dos pela comunidade local; } \\
\text { - no de alunos e colaboradores envolvi- } \\
\text { dos em atividades do setor de pastoral e } \\
\text { projetos de voluntariado. }\end{array}$ \\
\hline $\begin{array}{l}\text { Comunidade } \\
\text { educativa e } \\
\text { relacionamento }\end{array}$ & $\begin{array}{l}\text { - Ser reconhecido pelos alunos, colabora- } \\
\text { dores e familias como uma instituição refe- } \\
\text { rência em educação, inovação e processos } \\
\text { formativos. } \\
\text { - Ser reconhecido pela comunidade pelo } \\
\text { trabalho pastoral, formação humana e } \\
\text { comprometimento social. }\end{array}$ & $\begin{array}{l}\text { - No de alunos aprovados em vestibulares; } \\
\text { - resultado do ENEM; } \\
\text { - no de alunos destaques em olimpíadas } \\
\text { e feiras de conhecimento; } \\
\text { - nº de projetos pastorais reconhecidos e } \\
\text { premiados; } \\
\text { - market share. }\end{array}$ \\
\hline $\begin{array}{l}\text { Processos } \\
\text { internos }\end{array}$ & $\begin{array}{l}\text { - Qualificar e padronizar os processos pe- } \\
\text { dagógicos, pastorais. } \\
\text { - Padronizar e aprimorar os processos } \\
\text { administrativos. }\end{array}$ & $\begin{array}{l}\text { - \% de satisfação de alunos, pais e } \\
\text { colaboradores. }\end{array}$ \\
\hline $\begin{array}{l}\text { Desenvolvimento } \\
\text { humano e apren- } \\
\text { dizado }\end{array}$ & $\begin{array}{l}\text { - Promover uma cultura de melhoria contí- } \\
\text { nua, profissionalização, inovação e com- } \\
\text { prometimento com os valores lassalistas. }\end{array}$ & $\begin{array}{l}\text { - Horas de reunião pedagógica; } \\
\text { - horas de treinamento e capacitação; } \\
\text { - n de encontros e formações sobre a } \\
\text { missão lassalista. }\end{array}$ \\
\hline
\end{tabular}

Fonte: Elaboração própria. 
Percebe-se que o modelo de gestão proposto permite às escolas da Rede La Salle qualificar a atuação organizacional, caracterizada pela educação de qualidade, educação integral da pessoa e vivência dos valores lassalistas. Os objetivos estratégicos da unidade foram incorporados nas perspectivas do BSC, integrados e alinhados por meio da relação de causa e efeito. A elaboração de indicadores de desempenho para cada uma das quatro perspectivas do BSC possibilita uma análise constante de quais áreas estão correspondendo ao planejado e quais precisam de alterações para o alcance da estratégia, gerando um constante ciclo de aprendizagem e de qualificação de processos e resultados.

\section{Considerações finais}

O presente artigo teve como objetivo apresentar um modelo de gestão estratégica, para a Rede La Salle. Essa rede, assim como as demais redes e escolas confessionais, sofreu forte impacto com as alterações da LDB de 1996, e ainda está estruturando seus processos de gestão, conforme sinalizado por Trevisan e Trevisan (2010).

A implementação de uma cultura de gestão estratégica auxiliou a Rede a reverter o quadro de perda de alunos, retomando o crescimento do número de estudantes. Entretanto, diante de um mundo dinâmico, competitivo e tecnológico, a Rede La Salle entende que é importante continuar fiel aos princípios pedagógicos do seu fundador, ao mesmo tempo que é fundamental estar atento às características do mundo atual, no sentido de adotar ferramentas de gestão, necessárias à manutenção das obras e missão organizacional.

Os resultados encontrados auxiliaram na compreensão do processo de implantação de uma gestão estratégica na Rede. Percebeu-se que esse processo foi lento e que encontrou muitas dificuldades e resistências, tendo em vista a introdução de um modelo de administração estratégica em uma cultura não estratégica. Entre as ações realizadas, destacam-se: a padronização de processos; estabelecimento de metas e indicadores de desempenho; a criação de um primeiro modelo de gestão; a decisão estratégica de atuação em Rede. Como conquistas, percebeu-se a institucionalização de uma cultura de busca de resultados e o crescimento da Rede. Posteriormente, foi apresentada uma proposta de novo modelo de administração. O modelo proposto, ao utilizar as perspectivas do BSC, permite às escolas da Rede La Salle qualificar o processo de gestão estratégica, explorando a identidade confessional. Por fim, foi apresentada uma proposta de mapa estratégico e de respectivos indicadores de desempenho de uma unidade da Rede, para facilitar a visualização da aplicação do modelo proposto.

Este trabalho contribui com o aprimoramento da gestão estratégica da Rede La Salle, através da atualização do modelo de administração, a partir do BSC. Este artigo também contribui com a discussão do tema da em instituições educacionais confessionais, tendo em vista os escassos estudos nessa área. Deseja-se que este estudo possa auxiliar gestores de escolas confessionais a qualificar a sua gestão, garantindo a perenidade dessas escolas, tendo em vista a sua importância histórica, social e educativa para o país. Recomenda-se, como oportunidade de aprofundamento, a realização de pesquisas sobre o desempenho organizacional após a implementação de modelos de gestão estratégicas, baseados no BSC, em escolas confessionais, analisando a adaptações das mesmas ao modelo e o desempenho organizacional obtido.

\section{Referências}

ASSOCIAÇÃO NACIONAL DAS ESCOLAS CATÓLICAS. Pesquisa Nacional da Educação Básica: Desafios e Oportunidades. Brasilia, DF: ANEC, 2017.

BRASIL. Lei de Diretrizes e Bases da Educação Nacional, LDB. Brasilia: Ministério da Educação, 1996.

BOSCHILIA, R. Modelando Condutas: A educação católica em colégios masculinos (Curitiba, 1925-1965). 2002. Tese (Doutorado em História) - Universidade Federal do Paraná, Curitiba, 2002.

BRIGHENTI, A. A missão evangelizadora no contexto atual: Realidades e desafios a partir da América Latina. São Paulo: Paulinas, 2006.

BUFFA, E. A Igreja Católica enquanto grupo de pressão na tramitação da LDB. Pro-Posições, v. 25, n. 1. p. 141-159, 2014. https://doi.org/10.1590/S010373072014000100008 
CARVALHO, T. M. Gestão Estratégica e Gestão Educacional: uma integração por meio da metodologia do Balanced Scorecard aplicado a realidade da escola de Educação Básica. 2005. Dissertação (Mestrado em Gestão Educacional) - Universidade do Vale do Rio dos Sinos, Porto Alegre, 2005

CENTRO DE ESTATISTICA RELIGIOSA E INVESTIGAÇÕES SOCIAIS. Perspectiva da escola católica no Brasil. Baurú: ANAMEC; Ed.Universidade do Sagrado Coração de Jesus, 2006.

DALVIT, J. O. A Gestão nas Instituições de Ensino de Educação Básica: As Escolas da Rede La Salle do Rio Grande do Sul. São Leopoldo: Unisinos, 2007. Dissertação (Mestrado em Administração) - Universidade do Rio dos Sinos, Porto Alegre, 2007.

KUZMA, Cesar. O papel dos educadores leigos na escola católica. In: TESCAROLO, Ricardo. (Org.). Escolas Católicas diante de um novo tempo. Curitiba: Positivo, 2013. p. 86-116.

KAPLAN, R.; NORTON, D. A estratégia em ação: balanced scorecard. Rio de Janeiro: Campus, 1997.

Mapas Estratégicos: convertendo ativos intangiveis em resultados tangiveis. Rio de Janeiro: Campus, 2004.

KROEHN, Márcio. A nova fronteira da educação. Isto É Dinheiro, 31 mar. 2017. Disponivel em: https://www. istoedinheiro.com.br/nova-fronteira-da-educacao

LÜCK, H. Perspectivas da gestão escolar e implicações quanto à formação de seus gestores. Revista Em Aberto, Brasilia, v. 17, n. 72, p. 11-33, 2000. https://doi. org/10.24109/2176-6673.emaberto.17i72.2116

MARIUCCI, S. E. O mercado da Educação e a Educação Católica: Uma abordagem sobre as mudanças na política de gestão educacional nas escolas católicas do Brasil. Porto Alegre: PUCRS, 2011. Dissertação (Mestrado em Educação) - Pontifícia Universidade Católica do Rio Grande do Sul, Porto Alegre, 2011.

MOURA, L. D. A educação Católica no Brasil: passado, presente e futuro. São Paulo: Loyola, 2000.

MURAD, A. Gestão e Espiritualidade: uma porta entreaberta. $3^{a}$ Ed. São Paulo: Paulinas, 2008.

NEELY, A.; BOURNE, M. Why measurement initiatives fail. Measuring Business Excellence, v. 4, n. 4, p 3-7. 2000. https://doi.org/10.1108/13683040010362283

PAIER, L. S. A. Trajetória da Escola Menino Jesus (1941-2008): Princípios, Identidade e Cultura Notre Dame. 2008. Dissertação (Mestrado em Educação) Universidade do Rio dos Sinos, São Leopoldo, 2008.

PAIVA, Vanilda (Org.). Catolicismo Educação e Ciência São Paulo: Loyola, 1991.

PARO, Vitor Henrique. Administração escolar: introdução critica. 17ª Ed. São Paulo: Cortez, 2012.

PEREIRA, Marcos Aurélio. A trajetória da Escola Católica no Brasil: alguns apontamentos de história sobre a escola Católica. In: TESCAROLO, Ricardo. (Org.). Escolas Católicas diante de um novo tempo. Curitiba: Positivo, 2013. p. 17-40.
RIBEIRO, M. L. S. História da Educação Brasileira. São Paulo: IBRASA, 1986

ROMERO, C. Hacer de la escuela, una buena escuela: prácticas y escenarios de gestión. Buenos Aires: Aique, 2009

SAVIANI, Dermeval. História das ideais pedagógicas no Brasil. $3^{\text {a }}$ Ed. Campinas: Autores Associados, 2011.

STEINBERG, H.; MARCATTI, L. Governança Corporativa Aplicada às Instituições de Ensino. In: COLOMBO, S. S. (Org.). Nos Bastidores da Educação Brasileira: a gestão vista por dentro. Porto Alegre: Artmed, 2010.

TREVISAN, A.; TREVISAN, F. Os Desafios da Gestão Financeira. In: COLOMBO, S. S. (Org.). Nos Bastidores da Educação Brasileira: a gestão vista por dentro. Porto Alegre: Artmed, 2010.

YIN, R. K. Estudo de caso: planejamento e métodos $3^{\mathrm{a}}$ Ed. Porto Alegre: Bookman, 2010.

\section{Alexandre de Souza}

Mestre em Administração pela Universidade do Oeste de Santa Catarina (Unoesc). Atualmente é Diretor do Colégio La Salle, em Xanxerê, SC, Brasil.

\section{Carlos Eduardo Carvalho}

Doutorado em Administração e Turismo pela Universidade do Vale do Itajai (UNIVALI). Atualmente, é professor pesquisador no Mestrado Profissional em Administração e no Doutorado em Administração da Unoesc.

\section{Endereço para correspondência}

Alexandre de Souza

Colégio La Salle

Av. La Salle, 758

Centro, 89820000

Xanxerê, SC, Brasil

Os textos deste artigo foram revisados pela Zeppelini Publishers e submetidos para validação do(s) autor(es) antes da publicação. 